\title{
Writer's cramp in spinocerebellar ataxia Type 1
}

\author{
Geeta Anjum Khwaja, Abhilekh Srivastava, Vijay Vishwanath Ghuge, Neera Chaudhry \\ Department of Neurology, GB Pant Hospital, New Delhi, India
}

\section{ABSTRACT}

Dystonia can be encountered in a small subset of patients with spinocerebellar ataxia (SCA), but task specific dystonia is extremely rare. We report a case of a 48-year-old male with confirmed SCA Type 1 (SCA1) with mild progressive cerebellar ataxia and a prominent and disabling Writer's cramp. This case highlights the ever-expanding phenotypic heterogeneity of the SCA's in general and SCA1 in particular.

Key words: Dystonia, movement disorder, spinocerebellar ataxia, Writer's cramp

\section{Introduction}

The spinocerebellar ataxias (SCAs) are a group of genetically heterogeneous neurodegenerative disorders characterized by cerebellar, pyramidal, extrapyramidal, cognitive, and peripheral nerve dysfunction in variable combination. Dystonia can be encountered in a small subset of patients with SCA, but task-specific dystonia (Writer's cramp) is extremely rare and has been reported only in association with stray cases of SCA Types 6, 7, and 14 worldwide. We report a rare case of genetically confirmed SCA Type 1 (SCA1) with a prominent and disabling Writer's cramp.

\section{Case Report}

A 48-year-old, nonalcoholic, male police officer, presented to us with 2 years history of very slowly progressive dysarthria and a mild gait imbalance noticed only during running and marching. For the past 4 months, he also complained of an abnormal posturing and stiffness of his right hand while writing. There was no abnormal posturing of the hand, or any

\section{Address for correspondence:}

Dr. Abhilekh Srivastava, Department of Neurology, GB Pant

Hospital, Jawahar Lal Nehru Marg, New Delhi - 110 002, India.

E-mail: mrabhilekh@gmail.com

\begin{tabular}{|l|l|}
\hline \multicolumn{2}{|c|}{ Access this article online } \\
\hline Quick Response Code: & Website: \\
\hline & www.ruralneuropractice.com \\
\hline & \\
\hline
\end{tabular}

other part of the body while carrying out any other activities of daily living. There was no history of any motor or sensory deficit or incoordination of the upper limbs. His history was insignificant and there was no history of a similar illness in his siblings or other family members.

On examination, vitals and general physical examination were normal. His higher mental functions were preserved and cranial nerves were intact. On motor examination, size, tone and power were normal in all the four limbs. His deep tendon reflexes were brisk, but plantars were bilaterally flexor. The sensory system was normal. On cerebellar examination, there was a mild dysarthria. There was no nystagmus, but a slight slowing of the horizontal and vertical saccades was observed. There was no incoordination in the upper limbs, but the heel-shin test was slightly impaired. Gait ataxia was minimal and noticed only during tandem walking. A task-specific dystonia in the form of a Writer's cramp with lifting of the right index finger off the pen and curling of the thumb and the last two digits was documented while writing. There was no evidence of dystonia at rest or extrapyramidal manifestations such as bradykinesia, rigidity, or tremor in any other part of the body.

In view of the history of a very mild, slowly progressive, cerebellar ataxia of long duration, slow saccades,

This is an open access article distributed under the terms of the Creative Commons Attribution-NonCommercial-ShareAlike 3.0 License, which allows others to remix, tweak, and build upon the work non-commercially, as long as the author is credited and the new creations are licensed under the identical terms.

For reprints contact: reprints@medknow.com

How to cite this article: Khwaja GA, Srivastava A, Ghuge VV, Chaudhry N. Writer's cramp in spinocerebellar ataxia Type 1. J Neurosci Rural Pract 2016;7:584-6. 
hyperreflexia and a prominent Writer's cramp, a possibility of inherited SCA with task-specific dystonia was kept.

His routine investigations including hemogram, blood sugar, liver, renal, thyroid function tests, and serum Vitamin B12 levels were all normal. He tested negative for antibodies to HIV, hepatitis C virus, and hepatitis B surface antigen. Electrocardiogram, X-ray chest, and ultrasonography abdomen were also normal. Magnetic resonance imaging brain revealed significant cerebellar hemispheric and vermian atrophy [Figure 1]. Genetic testing for SCA subtypes confirmed the diagnosis of SCA Type 1. His Writer's cramp responded well to botulinum toxin injection with a significant improvement in his handwriting [Figure 2].

\section{Discussion}

Dominantly inherited SCAs are a heterogeneous group (40 and counting) of neurodegenerative disorders identified by specific mutations. They predominantly affect the cerebellum and its connections and are characterized by prominent limb ataxia with impaired balance, gait, speech, and eye movements. Additional features may include cognitive, pyramidal, extrapyramidal, and peripheral nerve dysfunction. Movement disorders in the form of myoclonus, chorea, Parkinsonism, tremors, and dystonia have also been described. ${ }^{[1]}$ Dystonia is commonly seen only in SCA Types 17, 3, and 2. ${ }^{[2,3]}$ However, there are case reports of both focal and generalized dystonia in SCA Types 1,6 , $7,8,12,14,20$, and 36 as well..[1]

SCA1 is associated with abnormal cytosine-adenineguanine repeats on the ataxin 1 gene on chromosome 6 and can be accompanied by cognitive dysfunction, Parkinsonism, and dystonia in addition to ataxia. However, extrapyramidal features are more common in SCA Types 2 and 3 than SCA1. ${ }^{[4]}$ Jhunjhunwala et al. studied extrapyramidal manifestations in 85 patients of SCA Types 1, 2, and 3..$^{[5]}$ Overall dystonia was encountered in 13 of the $85(15.2 \%)$

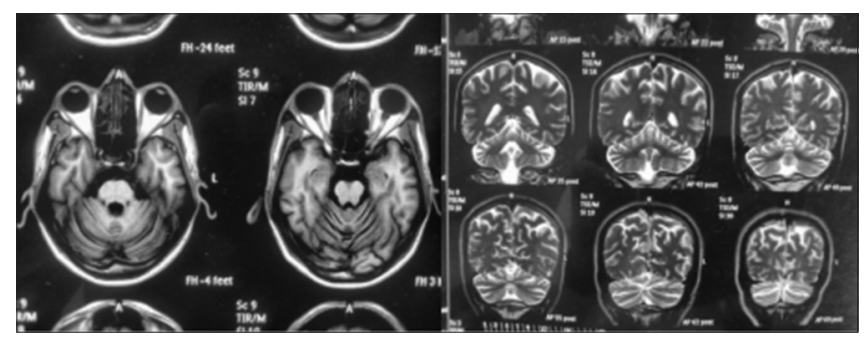

Figure 1: T1 axial and T2 coronal magnetic resonance imaging brain images showing cerebellar hemispheric and vermian atrophy cases only and was more common in SCA2 $(17.9 \%$, $n=5 / 28)$ and SCA3 $(17.6 \%, n=3 / 17)$ than SCA1 $(12.5 \%$, $n=5 / 40)$. In a study by Lee et al., extrapyramidal symptoms were found in 53\% SCA3 $(n=29)$ and $12 \%$ SCA2 patients $(n=17){ }^{[6]}$ None of the 6 cases with SCA1 had any evidence of extrapyramidal dysfunction in their cohort. Dragasevic et al. found dystonia in only $9.1 \%(n=33)$ of cases of SCA1 as compared to $44.4 \%(n=9)$ cases of SCA2. ${ }^{[7]}$ Cervical dystonia has also been reported as an initial manifestation of SCA1 and SCA2. ${ }^{[8]}$ In contrast to the usual pattern of focal or generalized dystonia reported in SCA1, our case presented with a prominent task-specific dystonia in the form of a Writer's cramp and added to the clinical spectrum of this subtype.

A review of the literature reveals that even in the SCA subtypes manifesting with dystonia, task-specific dystonia such as Writer's cramp is extremely rare. There are only stray case reports of Writer's cramp in SCA Types 6, 7, and 14 from all over the world [Table 1] and no reported case of this association in SCA1, as observed in our case.

Pathways implicated in the manifestation of dystonia include the cerebello-thalamocortical and basal ganglia-thalamocortical circuits. In a pathoanatomical study of patients with SCA1, Rüb et al. found neuronal loss and degeneration in these pathways besides the primary motor cortex and cerebellum..$^{[9]}$ It was also seen that the extent of the involvement of these structures correlated well with predominant clinical symptoms that were seen in an individual case. Dürr et al. have observed that the basal ganglia, especially the internal pallidum and the subthalamic nucleus show severe degeneration in SCA3 but are relatively spared in SCA1 which may account for the more frequent dystonia in SCA3. ${ }^{10]}$

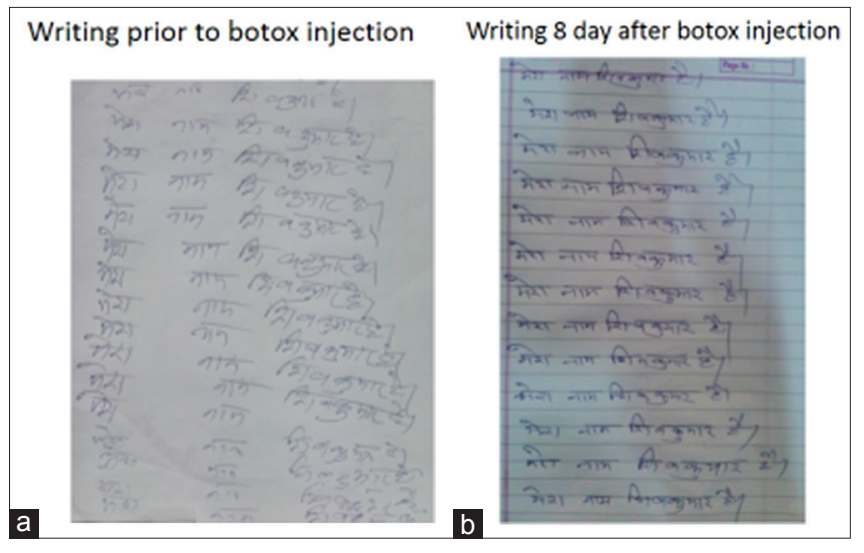

Figure 2: Handwriting specimen before (a) and after (b) botulinum toxin injection 
Table 1: Summary of reported cases of task specific dystonia in spinocerebellar ataxias

\begin{tabular}{|c|c|c|}
\hline Authors & Findings & Remarks \\
\hline Muzaimi et al. ${ }^{[1]}$ & SCA6 presenting with a task specific focal dystonia (Writer's cramp) & $\begin{array}{l}\text { Dystonia predated the onset of progressive } \\
\text { gait ataxia by } 5 \text { years }\end{array}$ \\
\hline Olszewska et al. ${ }^{[2]}$ & Familial SCA6 with a prominent Writer's cramp & $\begin{array}{l}3 \text { out of } 5 \text { affected members of the family had } \\
\text { the same focal dystonia }\end{array}$ \\
\hline Gaillard et al. ${ }^{[3]}$ & SCA7 with Writer's cramp & \\
\hline Roberto Erro et al. ${ }^{[4]}$ & SCA14 with Writer's cramp & $\begin{array}{l}\text { Writer's cramp predated the onset of cerebellar } \\
\text { ataxia as the first symptom by } 10 \text {-year }\end{array}$ \\
\hline Christos Ganos et al. ${ }^{[5]}$ & $\begin{array}{l}\text { task-specific or segmental dystonia with ataxia and myoclonus in } \\
\text { four German families with SCA14 }\end{array}$ & \\
\hline \multicolumn{3}{|c|}{$\begin{array}{l}\text { 1. Muzaimi MB, Wiles CM, Robertson NP, Ravine D, Compston DA. Task specific focal dystonia: A presentation of spinocerebellar ataxia type 6. J Neurol } \\
\text { Neurosurg Psychiatry 2003;74:1444-5. }\end{array}$} \\
\hline \multicolumn{3}{|c|}{ 2. Olszewska DA, Walsh R, Lynch T. SCA 6 with writer's cramp: The phenotype expanded. Movement Disorders Clinical Practice 2016;3:83-6. } \\
\hline \multicolumn{3}{|c|}{ 3. Gaillard N, Castelnovo G, Brice A, Labauge P. Writer's cramp secondary to spinocerebellar ataxia type 7. Rev Neurol (Paris) 2007;163:589-91. } \\
\hline \multicolumn{3}{|c|}{ 4. Erro R, Cordivari C, Edwards MJ, Foltynie T. Writer's cramp as the first symptom of spinocerebellar ataxia 14. Movement Disorders Clinical Practice 2015;2:41-2. } \\
\hline \multicolumn{3}{|c|}{$\begin{array}{l}\text { 5. Ganos C, Zittel S, Minnerop M, Schunke O, Heinbokel C, Gerloff C, et al. Clinical and neurophysiological profile of four German families with spinocerebellar } \\
\text { ataxia type 14. Cerebellum 2014;13:89-96. }\end{array}$} \\
\hline \multicolumn{3}{|l|}{ SCA: Spinocerebellar ataxias } \\
\hline
\end{tabular}

\section{Conclusion}

In SCA patients with Writer's cramp, the dystonia can precede, accompany or follow the onset of cerebellar ataxia. In our patient, Writer's cramp manifested almost $1 \frac{1}{2}$ years after the onset of the gait ataxia but subsequently became the most prominent and disabling complaint. To the best of our knowledge, this is probably the first case report of SCA1 with a task-specific dystonia or Writer's cramp. Our case highlights the ever-expanding phenotypic heterogeneity of the SCA's in general and SCA1 in particular.

\section{Financial support and sponsorship}

Nil.

\section{Conflicts of interest}

There are no conflicts of interest.

\section{References}

1. van Gaalen J, Giunti P, van de Warrenburg BP. Movement disorders in spinocerebellar ataxias. Mov Disord 2011;26:792-800.
2. Schmitz-Hübsch T, Coudert M, Bauer P, Giunti P, Globas C, Baliko L, et al. Spinocerebellar ataxia types 1, 2, 3, and 6: Disease severity and nonataxia symptoms. Neurology 2008;71:982-9.

3. Mariotti C, Alpini D, Fancellu R, Soliveri P, Grisoli M, Ravaglia S, et al. Spinocerebellar ataxia type 17 (SCA17): Oculomotor phenotype and clinical characterization of 15 Italian patients. J Neurol 2007;254:1538-46.

4. Schöls L, Peters S, Szymanski S, Krüger R, Lange S, Hardt C, et al. Extrapyramidal motor signs in degenerative ataxias. Arch Neurol 2000;57:1495-500.

5. Jhunjhunwala K, Netravathi M, Purushottam M, Jain S, Pal PK. Profile of extrapyramidal manifestations in 85 patients with spinocerebellar ataxia type 1, 2 and 3. J Clin Neurosci 2014;21:1002-6.

6. Lee WY, Jin DK, Oh MR, Lee JE, Song SM, Lee EA, et al. Frequency analysis and clinical characterization of spinocerebellar ataxia types 1, 2, 3, 6, and 7 in Korean patients. Arch Neurol 2003;60:858-63.

7. Dragasevic NT, Culjkovic B, Klein C, Ristic A, Keckarevic M, Topisirovic I, et al. Frequency analysis and clinical characterization of different types of spinocerebellar ataxia in Serbian patients. Mov Disord 2006;21:187-91

8. Boesch SM, Müller J, Wenning GK, Poewe W. Cervical dystonia in spinocerebellar ataxia type 2: Clinical and polymyographic findings. J Neurol Neurosurg Psychiatry 2007;78:520-2.

9. Rüb U, Bürk K, Timmann D, den Dunnen W, Seidel K, Farrag K, et al. Spinocerebellar ataxia type 1 (SCA1): New pathoanatomical and clinico-pathological insights. Neuropathol Appl Neurobiol 2012;38:665-80

10. Dürr A, Stevanin G, Cancel G, Duyckaerts C, Abbas N, Didierjean O, et al. Spinocerebellar ataxia 3 and Machado-Joseph disease: Clinical, molecular, and neuropathological features. Ann Neurol 1996;39:490-9. 